\title{
Influence of Exchange-Correlation Functional in the Calculations of Vertical Excitation Energies of Halogenated Copper Phthalocyanines using Time-Dependent Density Functional Theory (TD-DFT)
}

\author{
Sang Uck Lee \\ Department of Chemistry, University of Ulsan, Ulsan 680-749, Korea.E-mail: suleechem@ulsan.ac.kr \\ Received April 6, 2013, Accepted May 5, 2013
}

\begin{abstract}
The accurate prediction of vertical excitation energies is very important for the development of new materials in the dye and pigment industry. A time-dependent density functional theory (TD-DFT) approach coupled with 22 different exchange-correlation functionals was used for the prediction of vertical excitation energies in the halogenated copper phthalocyanine molecules in order to find the most appropriate functional and to determine the accuracy of the prediction of the absorption wavelength and observed spectral shifts. Among the tested functional, B3LYP functional provides much more accurate vertical excitation energies and UV-vis spectra. Our results clearly provide a benchmark calibration of the TD-DFT method for phthalocyanine based dyes and pigments used in industry.
\end{abstract}

Key Words : Absorption wavelength, Dye/pigments, Halogenation, Phthalocyanines, TD-DFT

\section{Introduction}

Phthalocyanines ${ }^{1-4}$ are a class of compounds that have received a great deal of interest in recent years as the second most important class of colorant because of their tinctorial power and superior properties such as outstanding stability to light, heat, acids and alkalis, and copper phthalocyanine is the single largest-volume colorant sold. In addition, their absorption may be extended into the near infrared by suitable chemical engineering. ${ }^{5-14}$ The properties and effects of these infrared-absorbing phthalocyanines are diverse and cover many important hi-tech applications, including photodynamic therapy, optical data storage, reverse saturable absorbers and solar screens. The majority of these applications exploit the unique optical properties of phthalocyanines, and thus a variety of spectroscopic techniques such as UV-vis spectroscopy, magnetic circular dichroism (MCD), and fluorescent as well as time-resolved fluorescent spectroscopy were used in the characterization of the excited states of phthalocyanines and their analogues.

For the prediction of the optical properties of phthalocyanines, especially vertical excitation energies, several methods have been used, such as the Pariser-Parr-Pople (PPP) ${ }^{15,16}$ method, the semi-empirical $\mathrm{CNDO} / \mathrm{S}^{17}$ and INDO/ $\mathrm{S}^{18}$ methods, and time-dependent density functional theory (TD-DFT) $\cdot{ }^{19-21}$ Further accuracy, beyond that achieved using semi-empirical methods, is needed for the design of new dyes and pigments. Recently, the TD-DFT method correctly reproduced the visible absorption of large organic molecules as well as dyes and pigments. ${ }^{22}$ Although TD-DFT methods significantly improve the prediction of vertical excitation energies, the type of exchange-correlation functionals should be considered for the reliability of TD-DFT methods.

In this work, we present an analysis of the structure and optical properties of the halogenated copper phthalocyanine (no,m $\beta(\mathrm{Hal})-\mathrm{CuPc}$ ) molecules using TD-DFT method coupled with 22 different exchange-correlation functionals including long-range corrected (LRC) functionals according to the variation in the substituted halogen atom species $(\mathrm{Hal}=\mathrm{Cl}$ or $\mathrm{Br}$ ) at the $\alpha$ and $\beta$ positions of isoindole ring with different number ( $\mathrm{n}$ and $\mathrm{m}=0,4,8$ or 16) in order (i) to determine the most appropriate functional; (ii) to determine the accuracy with which TD-DFT can predict the absorption wave-length of phthalocyanine based pigments; (iii) to determine the ability of TD-DFT to reproduce spectral shifts observed. We have compared the calculated absorption spectra with the experimental data for the conventional phthalocyanine blue and green pigments, Blue15, Green7, and Green36. Blue15 is a complex of copper with phthalocyanine and Green7 and Green36 are synthesized by replacing most of the hydrogen atoms of Blue 15 with halogen atoms (chlorine and bromine). We believe that the present results are important for the practical application of computeraided materials design using phthalocyanines and their analogues.

\section{Computational Details}

In this work, vertical transition energies were evaluated at the TD-DFT level of theory. The lowest-lying 40 core molecular orbitals which are attributed to $1 \mathrm{~S}$ orbitals of carbon atoms are excluded in the TD-DFT calculations. And 80 excited states are calculated to obtain the UV-visible absorption spectrum with the range of wavelength from around $380 \mathrm{~nm}$. We have compared the performance of widely used 22 DFT functionals - local density approximation (LDA) $\left(\mathrm{SVWN}^{23,24}\right)$, pure generalized gradient approximation (GGA) (BLYP, ${ }^{25}$ PW91 ${ }^{26}$ PBEPBE, ${ }^{27}$ BP86, ${ }^{28}$ VSXC $^{29}$ ), hybrid GGA (B3LYP, ${ }^{30,31}$ B3PW91, B3P86, B98, B1LYP, mPWPW91, ${ }^{32}$ PBE1PBE, BHandHLYP, ${ }^{33}$ and BHandH), 

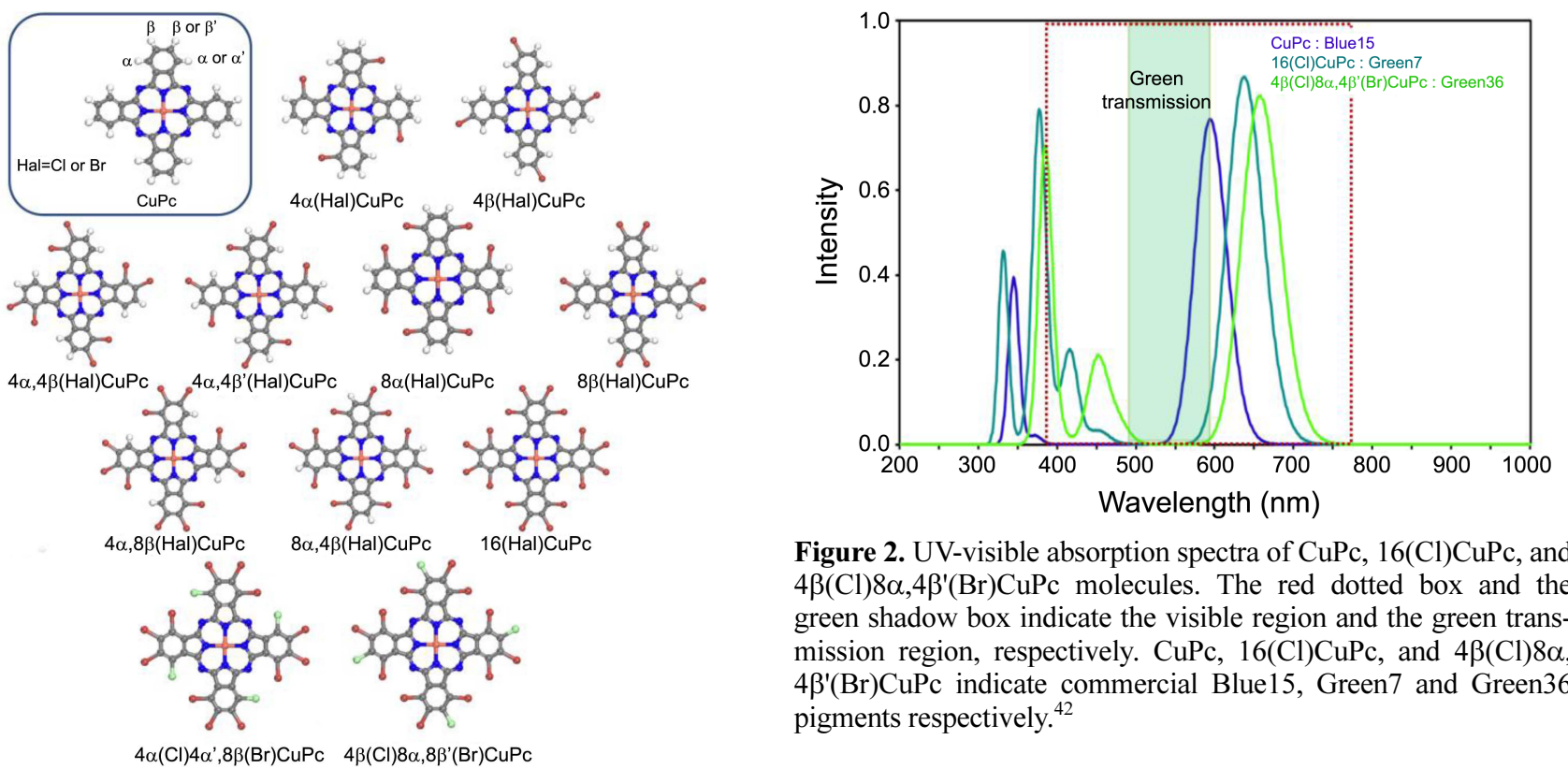

Figure 2. UV-visible absorption spectra of $\mathrm{CuPc}, 16(\mathrm{Cl}) \mathrm{CuPc}$, and $4 \beta(\mathrm{Cl}) 8 \alpha, 4 \beta^{\prime}(\mathrm{Br}) \mathrm{CuPc}$ molecules. The red dotted box and the green shadow box indicate the visible region and the green transmission region, respectively. $\mathrm{CuPc}, 16(\mathrm{Cl}) \mathrm{CuPc}$, and $4 \beta(\mathrm{Cl}) 8 \alpha$, $4 \beta^{\prime}(\mathrm{Br}) \mathrm{CuPc}$ indicate commercial Blue15, Green7 and Green36 pigments respectively. ${ }^{42}$

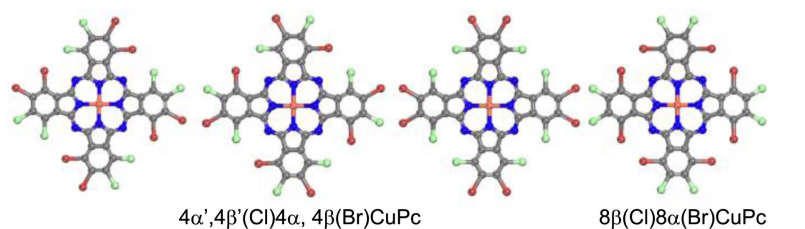

$4 \alpha, 4 \beta(\mathrm{Cl}) 4 \alpha^{\prime}, 4 \beta^{\prime}(\mathrm{Br}) \mathrm{CuPc}$ $8 \alpha(\mathrm{Cl}) 8 \beta(\mathrm{Br}) \mathrm{CuPc}$

Figure 1. Structures and abbreviations of copper phthalocyanine $(\mathrm{CuPc})$ and halogenated copper phthalocyanine molecules $(n \alpha, m \beta$ (Hal)-CuPc) in this study. ${ }^{42}$

and long-range corrected DFT(CAM-B3LYP, ${ }^{34}$ LC-BLYP, LC-OLYP, LC-PBEPBE, LC-wPBE, LC-TPSSTPSS, and LC-tHCTH) ${ }^{35}$ functionals- for the TD-DFT calculation. In addition, we have considered the amount of Hartree-Fock exchange for the hybrid GGA functional from $20 \%$ to $50 \%$. In this TD-DFT calculation, we have used the structures optimized at B3LYP/SDD level of theory, where the Stuttgart/Dresden double- $\zeta$ (SDD $)^{36,37}$ basis sets was used because Pople-type basis set does not support for bromine atom at the double- $\zeta$ level, such as 6-31G. The SDD basis sets treat 10 core electrons of the chlorine and bromine atoms and 28 core electrons of the copper atom with an effective core potential (ECP), and contract the valence basis sets from (8s7p6d) primitive sets to (6s5p3d). The effective core approximation includes relativistic contributions which become significant for the heavy atoms. In addition, because copper atom has unpaired electron, all calculations have been expanded to an unrestricted open-shell treatment. Vibrational frequency analyses have been carried out for all optimized $n \alpha, m \beta(\mathrm{Hal})-\mathrm{CuPc}$ structures at the same level of theory. All of the geometry optimization, vibrational frequency and TD-DFT calculations were carried out with GAUSSIAN $03^{38}$ software.

\section{Results and Discussion}

Structure and Energy of $\mathbf{n} \alpha, \mathbf{m} \beta(\mathrm{Hal})-\mathrm{CuPc}$. The $n \alpha$, $\mathrm{m} \beta(\mathrm{Hal})-\mathrm{CuPc}$ molecules are designed by replacing peripheral hydrogen atoms of copper phthalocyanine $(\mathrm{CuPc})$ molecule with different number ( $\mathrm{n}$ and $\mathrm{m}=0,4,8$ or 16) of substitutuents ( $\mathrm{Hal}=\mathrm{Cl}$ or $\mathrm{Br}$ ) at the $\alpha$ and $\beta$ positions of isoindole ring, and then we consider symmetry adapted conformational isomers as shown in Table 1 and Figure 1. If the halogen atoms are simultaneously substituted to $\alpha$ and $\alpha^{\prime}$ sites, the $n \alpha, m \beta(\mathrm{Hal})-\mathrm{CuPc}$ molecules may be deformed due to an interaction between substituted halogen atoms. As we will show later, the ability to quantify the out-of-plane deformations making up the distortion is crucial to obtaining an explanation of why large red-shifts are seen for the

Table 1. Designed halogenated copper phthalocyanine molecules $(n \alpha, m \beta(\mathrm{Hal})-\mathrm{CuPc})^{a}$

\begin{tabular}{|c|c|c|c|}
\hline & $\beta$ or $\beta^{\prime}$ & $N^{b}$ & Models \\
\hline & & 1 & $\begin{array}{l}4 \alpha(\mathrm{Hal})^{c} \mathrm{CuPc} \\
4 \beta(\mathrm{Hal}) \mathrm{CuPc} \\
\left(C_{4 \mathrm{~h}}\right)^{d}\end{array}$ \\
\hline & & 2 & $\begin{array}{l}4 \alpha, 4 \beta(\mathrm{Hal}) \mathrm{CuPc} \\
4 \alpha, 4 \beta^{\prime}(\mathrm{Hal}) \mathrm{CuPc} \\
8 \beta(\mathrm{Hal}) \mathrm{CuPc} \\
8 \alpha(\mathrm{Hal}) \mathrm{CuPc} \\
\left(D_{4 \mathrm{~h}} \text { or } D_{2 \mathrm{~d}}\right) \\
\end{array}$ \\
\hline 3 & $\begin{array}{l}4 \alpha, 8 \beta(\mathrm{Hal}) \mathrm{CuPc} \\
8 \alpha, 4 \beta(\mathrm{Hal}) \mathrm{CuPc} \\
\left(C_{4 \mathrm{~h}}, C_{4} \text { or } C_{2}\right)\end{array}$ & 4 & $\begin{array}{l}16(\mathrm{Hal}) \mathrm{CuPc} \\
\left(D_{4 \mathrm{~h}}, D_{4} \text { or } D_{2 \mathrm{~d}}\right)\end{array}$ \\
\hline $\begin{array}{c}4 \\
\text { (Mixed } \\
\text { form) }\end{array}$ & $\begin{array}{l}4 \alpha(\mathrm{Cl}) 4 \alpha^{\prime}, 8 \beta(\mathrm{Br}) \mathrm{CuPc} \\
4 \beta(\mathrm{Cl}) 8 \alpha, 4 \beta^{\prime}(\mathrm{Br}) \mathrm{CuPc} \\
\left(C_{4 \mathrm{~h}}, C_{2} \text { or } S_{4}\right)\end{array}$ & & $\begin{array}{l}4 \alpha, 4 \beta(\mathrm{Cl}) 4 \alpha^{\prime}, 4 \beta^{\prime}(\mathrm{Br}) \mathrm{CuPc} \\
4 \alpha, 4 \beta^{\prime}(\mathrm{Cl}) 4 \alpha^{\prime}, 4 \beta(\mathrm{Br}) \mathrm{CuPc} \\
8 \alpha(\mathrm{Cl}) 8 \beta(\mathrm{Br}) \mathrm{CuPc} \\
8 \beta(\mathrm{Cl}) 8 \alpha(\mathrm{Br}) \mathrm{CuPc} \\
\left(C_{4 \mathrm{~h}}, C_{2} \text { or } S_{4}\right)\end{array}$ \\
\hline
\end{tabular}

${ }^{a}$ All structures of copper phthalocyanine and halogenated copper phthalocyanine molecules in this study are listed in Figure 1. The abbreviated notations follow ref. 14. ${ }^{b}$ Number of halogen atoms per each isoindole fragment. ${ }^{c} \mathrm{Hal}=\mathrm{Cl}$ or $\mathrm{Br} .{ }^{d} \mathrm{The}$ available symmetry. ${ }^{e}$ Isoindole fragment has $\mathrm{Cl}$ and $\mathrm{Br}$ atoms without hydrogen atom. 
nonplanar n $\alpha, \mathrm{m} \beta(\mathrm{Hal})-\mathrm{CuPc}$ molecules.

Relative energies of the $n \alpha, \mathrm{m} \beta(\mathrm{Hal})-\mathrm{CuPc}$ molecules for different types of structures are listed in Table S1 in the Supporting Information. The $n \alpha, m \beta(\mathrm{Hal})-\mathrm{CuPc}$ molecules containing halogen atoms, up to three at each isoindole ring, prefer a planar structure by avoiding simultaneous substitution at the $\alpha$ and $\beta^{\prime}$ sites. Otherwise, if the $n \alpha, m \beta(\mathrm{Hal})-$ $\mathrm{CuPc}$ molecules are deformed, the saddle structure is energetically more stable than the planar or propeller structures. The energy difference is found to be larger for bromine $(\Delta \mathrm{E}$ $>\sim 4.0 \mathrm{kcal} / \mathrm{mol})$ than chlorine $(\Delta \mathrm{E}<\sim 2.0 \mathrm{kcal} / \mathrm{mol})$. The relative energy has been also investigated for mixed all halogenated $n \alpha, m \beta(\mathrm{Cl}) n^{\prime} \alpha, \mathrm{m}^{\prime} \beta(\mathrm{Br})-\mathrm{CuPc}$ molecules in Table S2 in the Supporting Information. All $n \alpha, m \beta(C l) n^{\prime} \alpha, m^{\prime}(\mathrm{Br})-$ $\mathrm{CuPc}$ molecules are stable in the deformed saddle structure, and it is likewise for the $16(\mathrm{Hal}) \mathrm{CuPc}$ molecules. Well-known commercial Blue15, Green7 and Green36 pigments respectively correspond to $\mathrm{CuPc}, 16(\mathrm{Cl}) \mathrm{CuPc}$ and $4 \beta(\mathrm{Cl}) 8 \alpha, 4 \beta^{\prime}(\mathrm{Br})-$ $\mathrm{CuPc}$ in our notation. It implies that the nonplanar deformation of the tetraazatetrabenzoporphyrin chromophore plays an important role in the manufacture of the commercial dyes and pigments.

Optical Properties of $n \alpha, m \beta(H a l)-C u P c$. Colored pigments which look green are characterized by two absorption maxima at 400-450 $\mathrm{nm}$ and 580-700 $\mathrm{nm}$ in the UV-visible absorption spectrum, and the other part of the light is transmitted. On the other hand, blue colored pigments have one absorption maximum in the long wavelength region, 600-700 nm. If we remember that Green7 and Green36 pigments are achieved by halogenation of the Blue15 pigment, it can be recognized that the halogenation leads to a change of the UV-visible absorption spectrum by the nonplanar deformation. Figure 2 shows the $\mathrm{UV}$-visible absorption spectra of $\mathrm{CuPc}, 16(\mathrm{Cl}) \mathrm{CuPc}$, and $4 \beta(\mathrm{Cl}) 8 \alpha, 4 \beta^{\prime}(\mathrm{Br}) \mathrm{CuPc}$ molecules, which are Blue 15, Green 7 and Green 36 pigments respectively. Blue15 has two absorption maxima, the Soret and Q bands. Each band is located in the UV region, $~ 340$ $\mathrm{nm}$, and the visible region, $\sim 600 \mathrm{~nm}$, respectively. Compared to Blue15, Green7 and Green36 show large red-shifts of the Soret and Q bands. The shift is twice as large for the Soret band than the Q band, which thus moves the Soret-band to the visible region, $400-450 \mathrm{~nm}$.

As mentioned in the previous computational details, the UV-visible absorption spectra have been calculated with 22 different DFT functionals (LDA, pure GGA, hybrid GGA, and LRC-DFT functionals) in comparison with experimental spectra for Blue15, Green7 and Green36 pigments in Figure 3 . In the case of hybrid GGA functionals, several types of functionals are available depending on the ratio of HartreeFock exchange, from $20 \%$ to $50 \%$. The amount of HartreeFock exchange affects the difference in energy between occupied and unoccupied molecular orbitals, which determines vertical excitation energies. Here, we considered 20\%, $21.98 \%, 25 \%$ and $50 \%$ of Hartree-Fock exchange. Previous literatures also reported the performance of DFT functionals for phthalocyanine and porphyrin based molecules and they addressed LDA and pure GGA functionals have a good
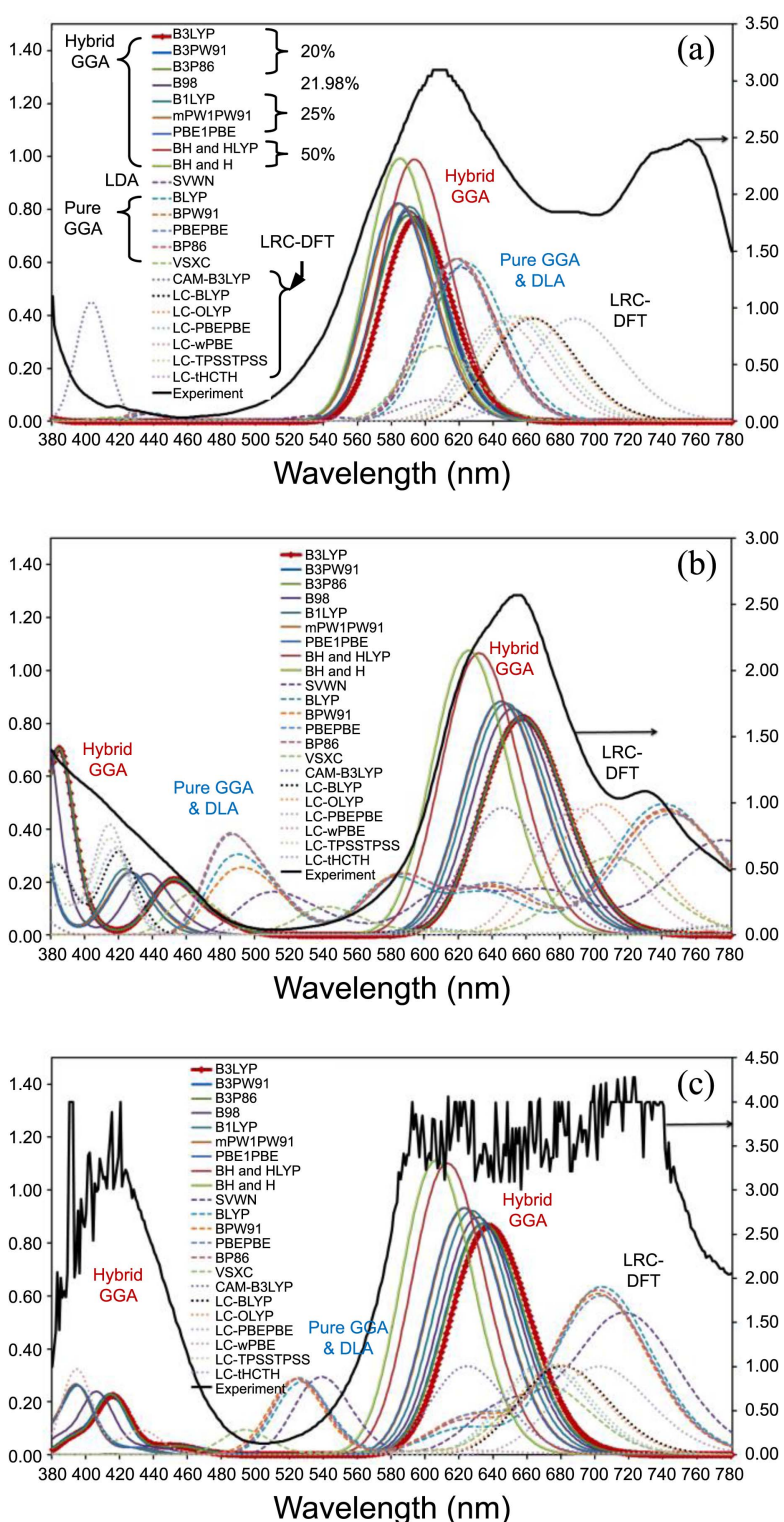

Figure 3. Calculated UV-visible absorption spectra of (a) $\mathrm{CuPc}$ (Blue15), (b) $4 \beta(\mathrm{Cl}) 8 \alpha, 4 \beta^{\prime}(\mathrm{Br}) \mathrm{CuPc}$ (Green36), and (c) 16(Cl)$\mathrm{CuPc}$ (Green7) at DFT level of theory with 22 different functionals (LDA, pure GGA, hybrid GGA, and LRC-DFT functionals) and experimental spectrum. Experimental absorbance is converted from transmitance data by Beer-Lambert law, $\mathrm{A}=\log (1 / \mathrm{T})$, where $\mathrm{A}=$ absorbance and $\mathrm{T}=$ transmitance. $^{42}$

agreement with experimentally observed UV-visible absorption spectra. ${ }^{39-41}$ However, the previous researches could not consider the halogenation effect, such as electronic and structural influence. In contrast, n $\alpha, \mathrm{m} \beta(\mathrm{Hal})-\mathrm{CuPc}$ molecules allow us to find the most appropriate functional and to determine the accuracy of the prediction of the absorption wave-length and observed spectral shifts. To compare the calculated absorption spectra with the experimentally observed transmittance, we converted the experimental transmittance to absorbance by Beer-Lambert law, $\mathrm{A}=\log (1 / \mathrm{T})$, where $\mathrm{A}$ $=$ absorbance and $\mathrm{T}=$ transmittance. $^{42}$

The calculated UV-visible absorption spectra of $\mathrm{CuPc}$ (Blue15) in Figure 3(a) shows all functionals except LRC- 


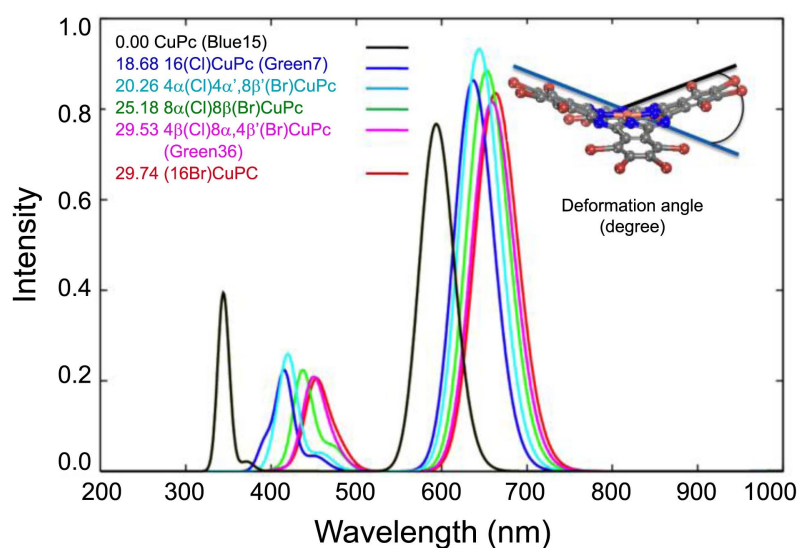

Figure 4. UV-visible absorption spectra of non-planar halogenated copper phthalocyanine molecules (n $\alpha, \mathrm{m} \beta(\mathrm{Hal})-\mathrm{CuPc})$ according to the deformation of the tetrabenzoporphyrin chromophore. The deformation angle is defined as seen in the inset. The numbers beside the molecule names refer to the deformation angles (in degrees). ${ }^{42}$

DFT showing largely red-shifted Q-band give a good agreement with experimental data although LDA and pure GGA functional show a little red-shifted $Q$ band around $620 \mathrm{~nm}$ compared to blue-shift of $\mathrm{Q}$ band at hybrid GGA functionals around $590 \mathrm{~nm}$, and hybrid GGA functionals give strongabsorption intensity. In contrast, UV-visible absorption spectra of halogenated $\mathrm{CuPc}$ (Green7 and Green36) molecules depend on the type of functionals, as shown in Fig. 3(b) and 3 (c). The results show that hybrid GGA functionals $(20-25 \%$ of Hartree-Fock exchange) provide a good agreement with experimental data for Green7 and Green36 pigments (even Blue15), while LDA and pure GGA functionals give an unexpected absorption peak around green transmission region $(480-580 \mathrm{~nm})$ because of the exaggerated red-shift of both Soret and $\mathrm{Q}$ bands by halogenation. It means LDA and pure GGA functionals underestimate the difference in energy between occupied and unoccupied molecular orbitals induced by halogenation. And, the "half-and-half" hybrid GGA functionals, such as BHandHLYP and BHandH, overestimate the vertical excitation energies of the halogenated green pigments (Green7 and Green36). In addition, LRC-DFT functionals still show largely red-shifted Q-band. The analysis of molecular orbital energy levels shows that LRC-DFT gives underestimated HOMO-LUMO gap. Therefore, the red-shifted Qband just can be understood from the underestimated HOMOLUMO gap, because Q-band corresponds to HOMO to LUMO+1 excitation.

In order to comprehend the reason why the halogenation induces such large red-shifts, we have attempted to verify the relation between the magnitude of the nonplanar deformation and the red-shift by analyzing the deformation angle with respect to the variation in the substituted halogen atom species $(\mathrm{Hal}=\mathrm{Cl}$ or $\mathrm{Br})$ at the $\alpha$ and $\beta$ positions of isoindole ring with different number ( $\mathrm{n}$ and $\mathrm{m}=0,4,8$ or 16). The deformation angles of $\mathrm{n} \alpha, \mathrm{m} \beta(\mathrm{Hal})-\mathrm{CuPc}$ are listed in Table S3 in the Supporting Information. The UV-visible absorption spectra regarding the magnitude of the defor- mation angle clearly shows the close dependency of the redshift on the deformation angle in Figure 4, where the molecules with deformation angles in increasing order of magnitude are $\mathrm{CuPc}(\mathrm{Blue} 15)<16(\mathrm{Cl}) \mathrm{CuPc}(\mathrm{Green} 7)<4 \alpha(\mathrm{Cl}) 4 \alpha^{\prime}$, $8 \beta(\mathrm{Br}) \mathrm{CuPc}<8 \alpha(\mathrm{Cl}) 8 \beta(\mathrm{Br}) \mathrm{CuPc}<4 \beta(\mathrm{Cl}) 8 \alpha, 4 \beta^{\prime}(\mathrm{Br}) \mathrm{CuPc}$ $($ Green36) $<16(\mathrm{Br}) \mathrm{CuPc}$. Furthermore, the difference in color between two commercial green pigments, Green 7 and Green36, can be discriminated by the deformation angle. The more deformed Green36 $\left(29.53^{\circ}\right)$ appears yellowish green with a larger red-shift and the less deformed Green7 $\left(18.68^{\circ}\right)$ appears bluish green with a smaller red-shift.

\section{Conclusion}

A TD-DFT approach coupled with 22 different exchangecorrelation functionals was used for the prediction of vertical excitation energies of the halogenated copper phthalocyanine (n $\alpha, \mathrm{m} \beta(\mathrm{Hal})-\mathrm{CuPc})$ molecules. In general, the TDDFT approach provides a more accurate description of both visible and ultraviolet regions of UV-vis spectra of $\mathrm{CuPc}$ in comparison to the more popular semi-empirical methods. It was found that the calculated vertical excitation energies of n $\alpha, \mathrm{m} \beta(\mathrm{Hal})-\mathrm{CuPc}$ correlate with the amount of HartreeFock exchange involved in the exchange-correlation functional. The hybrid generalized gradient approximation (GGA) functionals with $20-25 \%$ of Hartree-Fock exchange provide a good agreement with experimental data for all pigments, while LDA and pure GGA functionals give an unexpected absorption peak and the "half-and-half" hybrid GGA functionals overestimate the vertical excitation energies of the halogenated pigments and LRC-DFT functionals show largely red-shifted Q-band. When only a limited number of structural conformations are possible for the dye and pigment, the vertical excitation energies can be predicted with good accuracy. Especially B3LYP functional provides much more accurate UV-vis spectra than other hybrid GGA functionals. We have shown deviation of the vertical excitation energies according to the variation of dihedral angles, which reflects the spectral shifts between Green7 and Green36. It implies that the nonplanar deformation of the chromophore plays an important role in the manufacture of the commercial dyes and pigments.

The results clearly provide a benchmark calibration of the TD-DFT method for phthalocyanine based dyes and pigments used in industry. We believe that these data are important for the practical application of computer-aided materials design using phthalocyanines and their analogues.

Acknowledgments. This work was supported by the 2012 Research Fund of University of Ulsan.

\section{References}

1. Gregory, P. J. Porphyrins Phthalocyanines 2000, 4, 432-437.

2. Zollinger, H. Color Chemistry: Syntheses, Properties and Applications of Organic Dyes and Pigments; New York, VCH: Weinheim, 1987.

3. Kadish, K. M.; Smith, K. M.; Guilard, R. The Porphyrin Handbook 
Vol. 15-20; Academic Press: San Diego, 2003.

4. Leznoff, C. C.; Lever, A. B. P. Phthalocyanines Properties and Applications, Vol. 1; New York, VCH: 1989.

5. Lim, J. M.; Yoon, Z. S.; Shin, J. Y.; Kim, K. S.; Yoon, M. C.; Kim, D. Chem. Commun. 2009, 261-273.

6. Fukuda, T.; Kobayashi, N. Dalton Trans. 2008, 4685-4704.

7. Fukuda, T.; Ogi, Y.; Kobayashi, N. Chem. Commun. 2006, 159161.

8. Reddya, K. R. V.; Keshavayya, J. Dyes Pigm. 2002, 53, 187-194.

9. Mikhalenko, S. A.; Derkacheva, V. M.; Luk'yanets, E. A. Zh. Obshch. Khim. 1981, 51, 1650-1657.

10. Nemykin, V. N.; Kobayashi, N.; Nonomura, T.; Luk'yanets, E. A. Chem. Lett. 2000, 184-185.

11. Subbotin, N. B.; Nemykin, V. N.; Voloshin, Y. Z. Mendeleev Commun. 1993, 121-122.

12. Mikhalenko, S. A.; Korobkova, E. V.; Luk'yanets, E. A. Zh. Obshch. Khim. 1970, 40, 400-403.

13. Volkova, K. A.; Avramenkob, G. V.; Negrimovskiia, V. M.; Luk'yanetsa, E. A. Russ. J. Gen. Chem. 2007, 77, 1126-1133.

14. Kobayashi, N.; Ogata, H.; Nonaka, N.; Luk'yanets, E. A. Chem. Eur. J. 2003, 9, 5123-5134.

15. Pariser, R.; Parr, R. G. J. Chem. Phys. 1953, 21, 466-471.

16. Pople, J. A. Trans. Faraday Soc. 1953, 49, 1375-1385.

17. Bene, J. D.; Jaffé, H. H. J. Chem. Phys. 1968, 48, 1807-1813.

18. Ridley, J. E.; Zerner, M. C. Theoret. Chim. Acta 1973, 32, 111134.

19. Han, Y. K.; Lee, S. U. J. Chem. Phys. 2004, 121, 609-611.

20. Han, Y. K.; Lee, S. U. Chem. Phys. Lett. 2002, 366, 9-16.

21. Guillaumont, D.; Nakamura, S. Dyes Pigm. 2000, 46, 85-92.

22. Tozer, D. T.; Handy, N. C. Phys. Chem. Chem. Phys. 2000, 2, 2117-2121
23. Slater, J. C. The Self-Consistent Field for Molecular and Solids. Vol. 4: Quantum Theory of Molecular and Solids; McGraw-Hill: New York, 1974.

24. Vosko, S. H.; Wilk, L.; Nusair, M. Can. J. Phys. 1980, 58, 12001211.

25. Becke, A. D. Phys. Rev. A 1988, 38, 3098-3100.

26. Perdew, J. P. Phys. Rev. B 1986, 33, 8822-8824.

27. Perdew, J. P.; Burke, K.; Ernzerhof, M. Phys. Rev. Lett. 1996, 77, 3865-3868.

28. Perdew, J. P.; Yang, Y. Phys. Rev. B 1992, 45, 13244-13249.

29. Van, V. T.; Scuseria, G. E. J. Chem. Phys. 1998, 109, 400-410.

30. Becke, A. D. J. Chem. Phys. 1993, 98, 5648-5652.

31. Lee, C.; Yang, W.; Parr, R. G. Phys. Rev. B 1998, 37, 785-789.

32. Adamo, C.; Barone, V. J. Chem. Phys. 1998, 108, 664-675.

33. Becke, A. D. J. Chem. Phys. 1993, 98, 1372-1377.

34. Yanai, T.; Tew, D.; Handy, N. Chem. Phys. Lett. 2004, 393, 51-57.

35. Iikura, H.; Tsuneda, T.; Yanai, T.; Hirao, K. J. Chem. Phys. 2001, 115, 3540-3544.

36. Dolg, M.; Stoll, H.; Preuss, H. Theor. Chim. Acta 1993, 85, 441450 .

37. Bergner, A.; Dolg, M.; Kuechle, W.; Stoll, H.; Preuss, H. Mol. Phys. 1993, 80, 1431-1441.

38. Frisch, M. J. et al. Gaussian 03, Revision C.02. Wallingford, CT: Gaussian, Inc.; 2004.

39. Nemykin, V. N.; Hadt, R. G.; Belosludov, R. V.; Mizuseki, H.; Kawazoe, Y. J. Phys. Chem. A 2007, 111, 12901-12913.

40. Soldatova, A. V.; Kim, J.; Peng, X.; Rosa, A.; Ricciardi, G.; Kenney, M. E.; Rodgers, M. A. J. Inorg. Chem. 2007, 46, 2080-2093.

41. Rosa, A.; Baerends, E. J. Inorg. Chem. 1994, 33, 584-595.

42. Lee, S. U.; Kim, J. C.; Mizuseki, H.; Kawazoe, Y. Chem. Asian J. 2010, 5, 1341-1346. 